\title{
Reasons for Tourism Destination: A Conceptual Study on Young Generation in Bangladesh
}

\author{
Sabnam Jahan* \\ *Department of Management, Faculty of Business Studies, University of Dhaka, Bangladesh \\ Email Id:sabnam_jahan@yahoo.com
}

\begin{abstract}
Tourism has been proved as a major income driving industry in many middle income countries. In terms of income, employment opportunities and foreign exchange, tourism industry has contributed positively in Bangladesh. This research work is a conceptual study and dimensions related to social, travel, destination and miscellaneous aspects were considered to identify their influence on destination choices. The study depicted that decisions were generally influenced by aspects relating to safety, economics, infrastructural facilities and environment. The exogenous variables such as political instability and the level of crime rate in each destination are not vital determinants of tourist's choice of youngsters. Therefore, it can be implied that a uniform strategy for every age group will not be effective. There is a scope for future studies as a part of roadmap development of probable future promotion strategies for tourism in Bangladesh which can be done on customer perception to identify the decision-making path of domestic tourists of different age groups through in-depth research work.
\end{abstract}

Key Words: Tourism, young generation, Bangladesh, safety, infrastructure, economics.

\section{PAPER/ARTICLE INFO} RECEIVED ON: $12 / 03 / 2020$ ACCEPTED ON: 31/05/2020

Reference to this paper should be made as follows:

Sabnam Jahan (2020), "Reasons for Tourism Destination: A Conceptual Study on Young Generation in Bangladesh", Int. J. of Trade and Commerce-IIARTC, Vol. 9, No. 1, 213-220 
Reasons for Tourism Destination: A Conceptual Study on Young Generation in Bangladesh

\section{Sabnam Jahan}

\section{INTRODUCTION}

Expression of natural human instinct for experience, learning, and enjoyment can be defined as tourism. Tourism can be considered as one of the fastest-growing sectors in the economy employing around 225 million people and responsible for $11 \%$ gross domestic product (GDP) worldwide. Domestic tourism is rising rapidly now a day and predicted to be much higher than international tourism in the coming days. Many factors are accountable for this increase in the volume of the tourist flow, the surge in the number of high spending tourists, accelerated spread in the name of tourists geographically, pro-active government policies, and growing interest from investors. Domestic, outbound and inbound - call of the three kinds of tourism are facing Appreciable positive growth and acting as catalysts in the socio-economic development of the country. Therefore, it would not be wise to underestimate the role of domestic travellers in the development process of tourism. As the key to the future of tourism in Bangladesh is held by local tourism, it is essential to evolve a development model for tourism accordingly. This is not only because of the sheer volume and revenue generation but also for its reliability, consistency, resilience, less volatility, and lower cultural impacts in contrast to international tourism.

For decades, the reasons for choosing a travel destination have been an essential area of study in the literature of tourism. "Push and pull" model (Crompton, 1979) is a well-known typology for understanding travel motivation. The breakdown of an individual's choice of a travel destination into two forces is the main logic of this model. Push factors are those that push an individual away from home and attempt to develop a general desire to go somewhere else, without identifying where that may be. Pull factors are those that pull an individual toward a destination due to a region-specific enticement or perceived attractiveness of a target (Lam and Hsu, 2006). These are the two forces of the famous model. According to Tribe (2004), while choosing between a range of destinations, goods, and services, tourists would like to maximize satisfaction. While, as per se of Stabler et al., (2010), tourists' preferences and their expenditure budgets are the critical determinants in the decision making process. Expenditure budgets are not as hard to analyze as tourists' preferences from an economic point of view.

Additionally, social psychologists or geographers have analyzed the decision-making process more often. Focus on studies of motivation, tourist segmentation, and push and pull factors are followed by these researchers, while economists study tourists' preferences (Stabler et al., 2010). During deciding about their holiday and destination, many factors remain active that influence tourists. Horner and Swarbrooke (2007) stated that these factors could be internal, e.g., hobbies and interests, lifestyle, attitudes, past experiences, personality, etc. and external, e.g., word-ofmouth, promotions and offers, the climate, availability of suitable products, etc. it is essential for destination marketing and management to understand and analyze the decision-making process (Pearce, 2005). Law (1993) said that there could be several motives behind people visiting cities, and the probable reasons can be: visiting friends and relatives, business, exhibitions, cultural attractions, sightseeing, entertainment, shopping, evening activities, sports, and special events, etc. In the decision-making process, there are several alternatives for fulfilling a wide range of tourists' experience expectations. This is why Kolb (2006) has mentioned the importance of creating promotional strategies that communicate the benefits of visiting a city during the second phase of the decision-making process. The needs and desires of a specific visitor group or segment must be the primary focus of the promotion of a city.

The purpose of this paper is to find out which factors influence young people during the decisionmaking process. The motive of analyzing tourist motivation and activities is to explore visitors' 
desires, wants, and needs. Destination developers will be benefited from the analysis result to understand target markets and improve the products, services, and activities arranged for the tourists. These kinds of tourist motivation studies should be rigorously used in developing products, promotions, and marketing strategies. Destination marketing and development is playing an essential role in both theoretical and practical tourism business. As global tourism markets become more and more competitive, improved quality of their products and services by many tourism destinations enhance competitiveness.

\section{LITERATURE REVIEW}

A variety of merchandise and services is obtainable by every destination to draw in tourists. From the destinations' purpose of reading, it's vital to understand why tourists select or not select this destination and also the tourists' feelings concerning the place they visited. The theoretical and empirical proof on the causative relationship among the push and pull motivations, satisfaction. Destination loyalty is extended in many attempts to analyze traveller motivation (Yoon \& Uysal, 2005). Tourists' choices square measure advanced varied options wherever the alternatives of various necessities square measure reticular. Dellaert, Etterma, and Lindh (1998) over that this relation evolves in a very call method over time. The crucial part of the travel decision-making method is traveller destination alternative, known in most studies of tourists' travel alternatives. A variety of psychological (internal) and non-psychological (external) variables influence the decision-making method. Specific actions in numerous stages of square measure enclosed during this method. A comprehensive qualitative review of the traveller decision-making literature has been provided by Sirakaya and Woodside (2005) that have integrated the most abstract and empirical work that has been revealed within the touristy literature thus far. They found that the destination alternative set model developed by Um and Crompton (1990) is less complicated and additional in theory and methodologically sound than the others in touristy call analysis. Here a 3-stage successive and funnel-like method is employed to work out a tourist's destination alternative. The composition of awareness set is formed of the initial associate set of destinations that a traveller is alert to at any given time, associate elicited set called late thought set, and final destination alternative. The elicited set generated from the notice set, and it consists of different destinations that individuals actively ask for info concerning other options to best meet their desires. Consistent with the selection set model, the goal ought to be enclosed in every alternative set stage to be eligible as a final destination. The standards that affect this method embody personal (push) factors, destination attributes (pull factors), and constraints.

Crompton and Ankomah (1993) prompt that one may use two or three criteria to scale back the number of alternatives from the notice set to the elicited set; otherwise, there may be too several attributes to check. Additionally, Lam and Hsu (2006) mentioned that the advanced decisionmaking method resulting in the selection of a travel destination, had not been well researched. Past studies associated with destination alternatives primarily specialize in characteristic vital attributes moving destination choice; skilled judgment square measure the most ways (Goossens, 2000; Heung, Qu, \& Chu, 2001; Kim \& Prideaux, 2005; Kozak, 2002; Mutinda\& Mayaka, 2012). These studies have contributed to several specific issues; the 5-point (or 7-point) Likert scale was used for rating the importance of every factor, and also the elements extracted square measure organized so as of decreasing variance, however very little has been learned concerning the relative importance of everyone by pairwise comparison. Nicolau and Más (2006) identified fthe alternative| the selection\} of traveller destination that distinguishes between varied approaches to 
Reasons for Tourism Destination: A Conceptual Study on Young Generation in Bangladesh

Sabnam Jahan

the definition of traveller destination; they showed an outline of the empirical proof of destination choice with unconcealed and declared preference probabilistic models severally, as incontestable in Tables one and a couple of of their paper. Either the multinomial logit model or nested multinomial logit model is employed to research the selection of destination in most of these papers. Additionally to the on top of, the literature of destination alternative is targeted on the direct impact of destination attributes like costs and distance (Nicolau\&Más, 2006), climate (Hamilton \& Lau, 2004), quality, and rating (Goossens, 2000).

What is more, a variety of studies were involved with personal pleasure motivations that influence the destination choice; but, empirical alternative literature has devoted very little attention to the impact of traveller motivations on the choice of destinations (Nicolau \& Más, 2006). During this study, destination alternative is conceptualized as a Tourist's choice of a goal from a collection of other options; varied psychological feature factors set that choice. Determining the factors that influence people "s alternative destination is crucial in developing applicable promoting ways.

Age, income, gender, temperament, education, cost, distance, status, risk, and motivation, etc., square measure factors that affect alternative destinations (Hsu et al., 2009). of those factors, travel motivation has been a crucial space of study within the touristry literature for many years. As motivation may be a dynamic idea, it should vary from one person to a different, from one market section to a different, from one destination to a different, moreover as from one decisionmaking method to subsequent (Uysal\& Hagan, 1993). it's thus not stunning that the idea of motivation is taken into account as a component of market segmentation in touristry in several empirical investigations (Kozak, 2002; Yavuz, Baloglu, \&Uysal, 1998; Zhang \&Marcussen, 2007). Kozak (2002) offers an associate analysis of traveller motivations by examining British and German tourists WHO have visited Mallorca and Turkey. The findings show that non-public motivation and destination attributes ought to be used for destination positioning studies. Efforts to know the factors motivating tourists to go to a specific goal and the way seemingly it's to vary from those of different visiting other destinations might facilitate destination planners to line promoting approaches. It'll conjointly facilitate the goal to make a personality for promoting and differentiating its merchandise and services from those of competitive goals. One well-liked assortment for understanding travel motivation is that the push and pull model by Crompton (1979).

The push motivations are thought helpful for explaining the need for travel, whereas the pull motivations are considered useful for explaining the particular alternative of destination. Crompton actor seven socio-psychological (push) motivations (escape, self-exploration, relaxation, prestige, regression, kinship-enhancement, and social interaction) and two cultural (pull) motivations (novelty and education). Uysal and Jurowski (1994) summarized internal (push) and external (pull) motivators to travel. Internal motivators embody the need for escape, rest, relaxation, prestige, health and fitness, adventure, and social interaction. External motivators were supported the attractiveness of the destination, as well as tangible resources (beaches, recreational activities, and cultural attractions) and travellers" perceptions and expectations (novelty, profit expectations, and promoting image). In additional recent studies, researchers have more searching as a psychological feature characteristic of the destination (Hanqin\& Lam, 1999; Sirakaya, Uysal, \& Yoshioka, 2003). Oh, Uysal, and Weaver (1995) noted smart searching was thought-about as a pull item, associate attribute of the destination. There square measures still different vital factors like destination image, food, and safety. Milman and Pizam (1995) identified 
that destination image is that the visual or mental impression of a place control by the overall public. Goossens (2000) mentioned full the role representational process plays within the content of the pull force. Feeding is one of the foremost gratifying activities that tourists undertake throughout their holidays (Ryan, 1997). Quan and Wang (2004) found that food will act as either a primary or secondary trip motivation and adds price to the image of a destination. Safety is a primary concern for tourists (Middleton, 1994). Heung et al. (2001) found that security gave the impression to be the highest priority for each Hong Kong and Taiwan travellers. Travel motivation may be a multi-motive dimensional. Tourists typically have over one motive for selecting an exact destination; for instance, individuals will choose one goal with a purpose of relaxation in a charming, safe place combined with visiting a neighborhood historical heritage.

Ali and Mohsin (2008) commented that the touristry trade ought to be comprised of accumulating all courses of action that potency and effectiveness within the strategic promoting are being needed. Ali and Parvin (2010) represented that motivation may be a dynamic and versatile variable. The people's republic of Bangladesh ought to be a beautiful traveller destination composed of various factors for touristry like scenic beauty, archaeological, historical, cultural, business, spiritual and medical facilities, etc. The design of a motivation list should be versatile enough to include only changes across the life-span and take into account the results of broad cultural force on traveller motivation (Pearce, 1993). for instance, someone could modification his travel preferences as he moves through the family life cycle from a single-career person to an additional family-oriented person; his motives for selecting destinations could also be modified consequently.ILO(2020) represented thatCOVID-19 has dramatically altered the touristry sector, and square measure currently in a very significantly vulnerable position as governments have mandated the closure of all non-essential businesses, and plenty of firms have had no alternative, however, to minimize theirs in operation prices briefly. The impact on touristry enterprises and staff, the bulk being young girls, is new, as mentioned within the ILO sectoral temporary.

\section{Methodology}

In this paper, young people are defined as students between 18 and 35 years old who are currently studying. The research question is 'reasons for the young generation to decide their travel destination?' This study is mainly conceptual nature based on subjective judgment and used as a tool to collect, analyze, and interpret different secondary sources. The research is done during the pandemic situation in Bangladesh along with the globe due to COVID March 19 15, 2020, to June 10, 2020, for which we did not do any survey. Exact secondary sources will be mentioned.

\section{ANALYSIS OF THE FINDINGS}

The main goal of this study was to explore which reasons influence young people from Bangladesh, and the results revealed some factors among which safety seems to be the most influential factor. In connection with this, the most dominant item is Good and cheap accommodation. This is mostly related to the difficult economic situation in the entire country and especially among students who have a minimal travel budget as it was mentioned before. Accommodation costs represent a large portion of travel expenses, so, understandably, this item is the most dominant.

One of the essential items is also Hospitality, which can perhaps, in this case, be related also to Good food and drinks. Hospitality has always been highly valued throughout the history and tradition of the Serbian people as they always treated guests and visitors kindly and with 
Reasons for Tourism Destination: A Conceptual Study on Young Generation in Bangladesh

Sabnam Jahan

pleasure. Most people in the past and also today were raised and taught since they were children to be polite and kind to guests and visitors and treat them with the utmost respect and make them feel as comfortable as possible during their stay. This always implied plenty of good food and drinks and a pleasant company from the host. Hence, there is no wonder that people from Serbia give this so much meaning as they were raised in an environment that values these elements very highly and considers them as usual and expected.

Destination attractiveness and infrastructural facilities are ranked as the second most popular factor for a visit. This factor is somewhat related to the city destination ambiance and environment as well as its offer of natural and cultural heritage attractions. The most dominant item here is Weather, meaning that young people prefer visiting cities during spring and summer when it is warmer and with less rain which gives them more possibilities for various activities. This coincides with the fact that most city-break tours are organized during the spring and summer months. The other two items, Nature and Cultural heritage, are related to the city ambiance and surrounding environment as well as cultural heritage attractions and such elements as architecture, monuments, museums, and similar cultural institutions. Both items have very identical mean values. This can mean that most young people would prefer a more sophisticated city destination with a variety of attractions, both natural and cultural, over a goal with less or only one type of magnetism.

Finally, the results show that available and low-cost vacation is that the issue with significant influence on the visit of town destinations. This issue is usually associated with transport and also the chance to book everything online. The flexibility to book everything online is somewhat vital as a result of most of the youngsters in Bangla Desh typically still like travel agents and avoid rebooking. Most youngsters area unit a touch passive and don't wish to take a while and explore transport and accommodation potentialities by themselves and like this to be done by professionals even though it should price a touch additional however it saves them a while and offers them \{a better|a far better|a much better|a higher|a stronger| an extra robust|an improved sense of security as most of them typically have more trust in travel agencies than themselves. However, this is often slowly dynamic, and e-booking is obtaining more and more fashionable here because it is within the remainder of the planet. The reasons that have the smallest amount influence on the young generation area unit political instability and rate that indicates that they're least dominant things. With relevancy the decision-making method we tend to see that: In the selection of destination the motivations thought of most vital area unit the invention of latest cultures, the discovery of latest landscapes, contemplation of natural and inventive heritage, contact with area people, contact with nature; In the selection of accommodation value is that the most influential cause-issues additional relevant to property, just like the actual come back and profit to the area people from business, area unit thought of very little importance by the bulk of respondents; In the selection of a tour operator value is that the most critical issue (over sixty-seven think about it essential); the security of the journey and also the organization also are incredibly important; most respondents think about support for native development comes and environmental protection and even the involvement of native guides, to be quite vital. Most young tourists like native food, adapt the maximum amount as they'll to the traditions and customs of the place during which they're holidaying, attempt to study their destination before motion, would be willing to be concerned in events organized by the area people and to act with it, demonstrate interest within the protection of the credibility of the destination, notwithstanding this implies going while not sure comforts, resolve the way to shield 
the native surroundings and scale back waste, and area unit involved to make sure that their defrayal advantages the native population. However, ILO's (2020) 's observation concerning the business sector is below lock down the state of affairs in Bangladesh.

\section{LIMITATIONS AND IMPLICATIONS}

The main limitation of the analysis relates to abstract discussion solely attributable to the pandemic state of affairs. Future works ought to take away this disadvantage by investigating, an honest range of sample sizes at entirely different locations when the pandemic state of affairs is over. Besides, a form has to be improved to raised answer the analysis queries. In terms of analysis implications, this paper may be a place to begin for additional studies by providing AN understanding of traveling patterns of Bangladeshi youth supported relevant articles. Findings from this study will aid to each travel operators and repair suppliers at traveller destinations. For travel operators, they need AN understanding of what tourists concern about once buying a business package. They'll base on this info to style appropriate packages that higher meet customers' necessities. Therefore, travel agencies ought to specialize in satisfying customers rather than defrayal an excessive amount of effort on promoting as a result of once their customer's area unit is happy; their status can mechanically be improved through word-of-mouth assisting. For service suppliers, they ought to guarantee an exact level of security as a result of safety is that the most involved issue by tourists. If they do, therefore, they'll be ready to attract additional and additional young travellers visiting the destination wherever they are doing business. Overall, there ought to be in-depth cooperation between travel operators and repair suppliers at the goals if they require creating a long-run relationship with customers.

\section{REFERENCES}

[1]. Ali, Muhammad Mahboob and Mohsin, Chowdhury Sifat-e-(2009). Different Aspects of Tourism Marketing Strategies With Special Reference to Bangladesh: An Analysis. Khulna University Business Review-,6(1-2),91-106,,DOI: 10.35649/KUBR.2008.6.12.8 October

[2]. Ali, Muhammad Mahboob, and Parvin, Rehana (2010). Strategic Management of Tourism Sector in Bangladesh to raise Gross Domestic Product: An analysis. AIUB Bus Econ Working Paper Series, No 2010-04, http:// orp.aiub.edu/WorkingPaper/WorkingPaper.aspx?year=2010

[3]. Anil Kumar, K., 2008. Impact of negative factors of tourism on tourists, Southern Economist, 47(15):21-22.

[4]. Archer, B. (1976): Forecasting Tourism Demand, in S. Wahab (ed.), Managerial Aspects of Tourism, Cairo, Salah Wahab.

[5]. Arena, E. J., and Leon, J. C. (2008): Impact of terrorism on tourism demand, Annals of Tourism Research, Vol. 35, No. 2, pp. 299-315.

[6]. Babu. Sutheeshna, (2008), Spatial Dimensions of Tourism in India: A macro-level perspective. In Tourism Development Revisited: Concepts, Issues, and Paradigms, Response Books, Sage, New Delhi, pp 285-305

[7]. Burkart, A. J. and Medlik, S. (1981): Tourism: Past, Present and Future, Oxford, Heinemann.

[8]. Courch, G. Schultz, L. and Valerio, P. (1992) Marketing International Tourism to Australia, Tourism Management, June.

[9]. Domestic and International Tourism, Wellesley, MA: Institute of Certified Travel Agents, pp. 26-28. 
Reasons for Tourism Destination: A Conceptual Study on Young Generation in Bangladesh Sabnam Jahan

[10]. ILO (May revised,2020). The impact of COVID-19 on the tourism sector, ILO sectoral brief, https://www.ilo.org/wcmsp5/groups/public/---ed_dialogue/sector/documents/briefingnote/wcms_741468.pdf(viewed on June 2, 2020)

[11]. Knight, Frank H. (1921). Risk, Uncertainty, and Profit. Boston, MA: Hart, Schaffner \& Marx; Houghton Mifflin Company.

[12]. Nicholls, A., \& Young, R. (2008). Preface to the Paperback Edition. In A. Nicholls (Ed.), Social entrepreneurship: New models of sustainable social change (pp. vii-xxiii). Oxford, England: Oxford University Press.

[13]. Ramalingam, L.P., 2008. Tourism Industry and its potential. Quarterly Economic Report.

[14]. UNWTO, (2008), Tourism Highlights- 2008 Edition, UNWTO-OMT-IOHBTO, Madrid

[15]. UNWTO, (2009), Tourism and Economic Stimulus- Initial Assessment, Report, UNWTOOMT-IOHBTO, Madrid, July.

[16]. World Bank, (2009), Global Economic Prospects 2009, DEC Prospects Group World Bank, Forecast Update, March 2009. 